\title{
Indigenous health: Time for top-down change?
}

A year after the Truth and Reconciliation Commission's call to action, public health experts say indigenous health won't improve without major system change.

Last June, the commission issued a comprehensive treatment plan for healing the trauma inflicted on indigenous communities under Canada's residential schools system - but not much has happened. Eight of the commission's 94 recommendations directly addressed health care. So what's the hold up on high-level change?

That question dominated the recent Public Health 2016 conference in Toronto. Speakers described persistent inequity and inaction across the health system, from research to medical training to hospital care.

"The common response is to deny that the problem lies in the structures," said Charlotte Loppie, director of the Centre for Indigenous Research and Community-led Engagement at the University of Victoria in British Columbia.

She argued that it's a mistake to see "colonization" as something that happened in the past. "It's about the control that some people have over other people, which obviously continues today in the health policies and programs that are developed and expanded on indigenous communities, rather than with those communities."

\section{Research}

Loppie spoke at a panel hosted by the Canadian Institutes of Health Research (CIHR), which faced criticism in February for awarding less than $1 \%$ of funding to Aboriginal health projects in its first major competition since restructuring.

"We know we have to work to get this right and get this better and I think we're learning as we go," said Nancy Edwards, scientific director of the Institute of Population and Public Health at CIHR.

According to Edwards, Aboriginal health is now a "standing item" at sci-

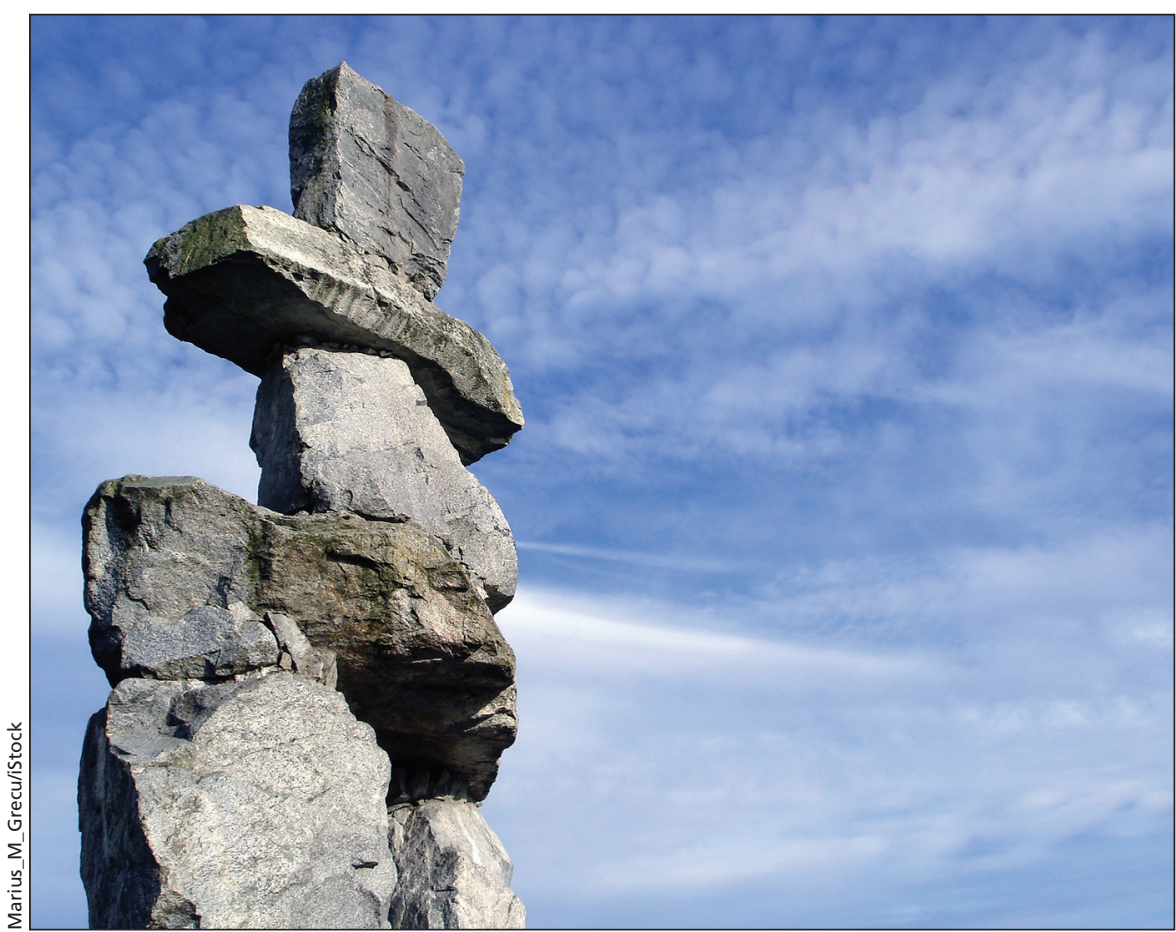

Speakers at the Canadian Public Health Association's annual conference urged structural change to improve indigenous health.

ence council meetings, which bring together CIHR top brass every four to six weeks. There has also been "a lot of consultation" with indigenous researchers and communities. There isn't a single barrier standing in the way. "It's not that simple," she said.

Loppie said she considers Edwards an ally, but noted that CIHR has "a long way to go" to correct the disadvantage to Aboriginal health research under the new funding structure. "Change is a difficult point," particularly at the most senior levels of administration, she said.

\section{Medical education}

Australia's experience integrating indi genous health education into medical training shows how change at that level can help transform a system.

Australia's version of a Truth and Reconciliation Commission recommended compulsory courses for all health professionals in 1989. But this didn't become reality for doctors until
2006, when the Australian Medical Council set standards that the indigenous health training schools must provide.

With accreditation on the line, change was rapid and meaningful, said Janie Smith, a professor of innovations in medical education at Bond University in Australia. "If you don't meet the standards, you can't run your program, so it's very powerful."

Bond's medical program overhauled its case-based curriculum to include indigenous examples to teach core concepts. Students also complete a two-day cultural immersion workshop in first year and a remote clinical placement in fifth year.

"It's a really important principle that this is the normal program and it's funded out of the normal budget," Smith said. Integration in core curriculum teaches students that cultural sensitivity is fundamental to being a good doctor, like understanding anatomy. It also protects indigenous health education from 
"toe cutters" when budgets are tight.

Although Canadian medical schools are expanding their indigenous health content, some educators noted that it's still peripheral to core training.

Lloy Wylie teaches medical students as an assistant professor of public health at Western University in London, Ontario. She recalled one indigenous health session that only a third of students attended. "When it's voluntary, only the people who don't need the training show up."

\section{Hospital care}

Wylie said she encountered the same indifference among some medical colleagues at Victoria Hospital in London, Ont., where she is appointed to the psychiatry department. "There are still some very unsettling things that I see going on in our hospital system."

She shared stories of "huge jurisdic- tional gaps" between the hospital and reserve, of patients with cancer denied adequate pain medication because of assumptions about addiction, and of health workers "woefully unaware" of indigenous culture and services.

"People in the hospital weren't even aware of the Aboriginal patient liaison that was in the hospital," Wylie said.

There are some recent bright spots; for example, British Columbia and Ontario are boosting cultural sensitivity training for health workers. But Wylie noted that the same workers "go back to institutions that are very culturally unsafe, so we need to look at changing those institutions as a whole."

Brock Pitawanakwat, an assistant professor of indigenous studies at the University of Sudbury in Ontario, cited the importance of creating space for traditional healing alongside clinical care. In some cases, it's a physical space:
Health Sciences North in Sudbury has an on-site medicine lodge that provides traditional ceremonies and medicines.

These services are as much about healing mistrust as any physical remedy, Pitawanakwat said. "Going into a hospital after attending a residential school, there's still that negative emotion," he explained. "If you look at these buildings in archival photos, they're almost identical."

Wylie suggested that the fee-forservice model could also be changed to support physicians building better relationships with patients.

"Anything we do to make our hospitals more welcoming places for Aboriginal people will be good for everybody," she said. "Right now, they're really alienating for everybody." Lauren Vogel, CMAJ

CMAJ 2016. DOI:10.1503/cmaj.109-5295 